\title{
O ENSINO/APRENDIZADO DE DESENHO TÉCNICO EM CURSOS DE ENGENHARIA
}

\author{
D. D. SOBRAL FILHA, J. ABRANTES, R. M. GRAMADO*
}

\begin{abstract}
Resumo
Este artigo tem como objetivo principal dissertar sobre a importância do ensino/aprendizado de Desenho Técnico, nos mais diversos cursos de engenharia. O que justifica este artigo é o fato de muitos cursos de engenharia no Brasil terem reduzido a carga horária total de disciplinas que tratam de expressão gráfica, sendo que em vários cursos, todo o conteúdo foi reduzido a uma única disciplina, com alguns poucos exemplos de desenhos técnicos sendo executados via computador. Ou seja, alunos são "adestrados" em alguns comandos de determinados programas (softwares), executam alguns exemplos e pronto: considera-se que os alunos já tenham conhecimento pleno sobre Desenho Técnico, ou melhor, sobre expressão ou representação gráfica! Será?Buscamos contudo elucidar a importância do ensino/aprendizagem do Desenho Técnico como fruto do conhecimento matemático ligado sobretudo ao desenvolvimento da visão espacial voltado à execução de projetos dos futuros formandos em engenharia.
\end{abstract}

\section{Introdução}

O que é um Desenho Técnico? Quais tipos de desenhos técnicos existem? Por que engenheiros têm que estudar Desenho Técnico? O Desenho Técnico é uma forma de expressão gráfica que tem por finalidade a representação de forma, dimensão e posição de objetos de acordo com as diferentes necessidades requeridas pelas diversas modalidades de engenharia, arquitetura e desenho industrial. Os desenhos técnicos podem ser projetivos ou não.

Desenhos técnicos são projetivos, quando um objeto, peça ou construção é representado pelas vistas ortográficas, ou melhor, por projeções cilíndricas ortogonais, como conceituadas por Gaspar Monge (17461818) em 1795, e normalmente estudadas na disciplina Geometria Descritiva (MONTENEGRO, 1991). Detalhes de construções civis, peças de máquinas e equipamentos, objetos em madeira, plásticos e em outros tipos de materiais, são exemplos de onde se aplicam os desenhos técnicos projetivos. Desenhos técnicos não projetivos são representações gráficas esquemáticas, que não seguem as projeções cilíndricas ortogonais. Diagramas, esquemas e fluxogramas são exemplos destes tipos de desenhos.

Independentemente da área em que atua, todo engenheiro, na sua essência, é um resolvedor de problemas. A prática da engenharia mostra que, antes de resolver um problema, o engenheiro tem que entendê-lo, visualizá-lo mentalmente e imaginar como modelá-lo tridimensionalmente. Essa característica, da atuação do engenheiro, o obriga a ter bem desenvolvidas, além dessa visão espacial ou tridimensional, outras habilidades (ou inteligências) específicas. A linguagem ou forma de se expressar básica da

\footnotetext{
*IME, doraliceduque@ime.uerj.br, abrantes@ime.uerj.br, rmgra@ime.uerj.br.
} 
engenharia são os desenhos técnicos, que nada mais são que as representações de objetos espaciais (tridimensionais ou X, Y, Z) em um plano bidimensional (X, Y).

$\mathrm{Na}$ prática, engenheiros usam os desenhos técnicos nas seguintes situações: interpretação e conservação (manutenção) de máquinas, sistemas ou construções. Dessa forma, utiliza-se o desenho para criar projetos novos ou modificar os já existentes. Em verdade, a expressão gráfica, via desenhos técnicos, constitui-se numa linguagem universal, comum a todos que dela necessitam.

No que se refere ao ensino da Geometria Descritiva, especialmente para cursos de Engenharia, é importante citar Rabello (2005, p.49), que lecionou essa disciplina, durante muitos anos (entre $1994 \mathrm{e}$ 2015), no Instituto de Matemática e Estatística da Uerj - IME/Uerj:

O ensino de desenho entrou em franco declínio no Brasil na década de 70, deixando de ser ministrado nos níveis fundamental e médio. A repercussão disso nos cursos superiores foi imediata. Muitos estudantes de engenharia e arquitetura chegaram mesmo a aceitar a ideia de que épura é uma deusa grega ou de que existem vetores curvos. Diante de fatos dessa gravidade, a necessidade de promover mudanças é urgente. Como a boa formação de engenheiros e arquitetos depende do conhecimento de geometria de posição e de procedimentos gráficos para representar formas, é fundamental que o aluno desses cursos se familiarize com as bases elementares do desenho geométrico e, em seguida, extraia da geometria descritiva o mínimo indispensável para desenvolver seu raciocínio espacial.

Rabello (2005, p.50) complementa: "Salvo raras exceções, os alunos que ingressam no ciclo básico, especialmente os do curso de Engenharia, não distinguem os ângulos de um esquadro ou um elipsóide de um rinoceronte".

Salientamos que não adianta apenas ensinar os comandos dos softwares para que os estudantes façam desenhos de forma automática, sem entender o conceito. Na prática, quem desenha com exatidão são os profissionais específicos, chamados desenhistas e projetistas. Somente em casos muito específicos, o engenheiro faz algum desenho com precisão via computador. Dessa forma, ensinar ou dar prioridade ao uso de uma ferramenta acarreta na diminuição dos conteúdos específicos da disciplina que irá realçar as inteligências verbo-linguística, lógico-matemática, viso-espacial e pictórica, essenciais ao exercício profissional da Engenharia.

Com relação à importância do ensino da Geometria Descritiva nos cursos de Engenharia é mister citar Torres, Vieira e Martins Filho (1998, p. 313):

Para criar, o engenheiro precisa de sua mente criativa. Para executar o objeto de sua imaginação, precisa comunicar-se. A comunicação será realizada pela expressão gráfica do objeto, ou seja, através de suas projeções cilíndrico-ortogonais em planos de projeção, também denominadas vistas ortográficas.

É através do raciocínio abstrato desenvolvido ao longo do curso por disciplinas como a Geometria Descritiva e o Desenho Técnico que o futuro profissional de engenharia encontrará o suporte para desenvolver o seu potencial criativo, o raciocínio lógico, que tanto auxiliam na utilização da linguagem gráfica que permitirá decodificar seu produto e torná-lo exequível.

Autores há que consideram a Geometria Descritiva obsoleta. Amorim ${ }^{6}$ e Laterza ${ }^{6}$ consideram que a Geometria Descritiva perde importância na medida em que desenvolve-se a computação gráfica.

Com efeito, a flexibilidade na simulação virtual, a destreza e precisão na execução dos trabalhos realizados com esta tecnologia, são fatores que influenciam significativamente nas disciplinas que se expressam pela representação gráfica. Mas não a invalidam. Ao contrário, as reforçam. A capacidade intelectual cada vez mais requisitada para o domínio da ferramenta computacional é desenvolvida por 
disciplinas estimuladoras do raciocínio espacial, lógico e crítico, onde incluímos a Geometria Descritiva.

"Não desprezo, e até valorizo muito, o uso dos recursos tecnológico/computacionais, mas entendo que eles devem ser utilizados posteriormente ao aprendizado dos principais conceitos envolvidos na GD, que constituirão uma base importante para o uso mais adequado desses recursos". (BOANOVA, 2011, p.46). Seguindo esse raciocínio, é importante citar Torres, Vieira e Martins Filho (1998, p. 316):

As ferramentas computacionais facilitam o desenvolvimento de projetos complexos, mas não substituem o homem em seu processo criativo. A tecnologia alimenta-se do saber. Assim é imprescindível que o futuro engenheiro desenvolva a capacidade de propor soluções inovadoras a partir do domínio de técnicas e processos de criação. Deve estar habilitado a enfrentar os desafios de seu tempo e em especial os múltiplos aspectos de sua inserção na sociedade. Necessita de raciocínio lógico e plástico, domínio da linguagem oral, escrita, gráfica, visual, perceptiva e capacidade de análise crítica, avaliação e decisão.

Assim sendo, o ensino da Geometria Descritiva deve orientar-se em contribuir para uma sólida formação do futuro engenheiro, ajudando-o a enfrentar desafios das rápidas transformações da sociedade, do mercado de trabalho e das condições de exercício profissional.

\subsection{As Projeções Cilíndricas Ortogonais}

A Geometria Descritiva usa um sistema de projeção cilíndrica e ortogonal, ou seja, como pertencentes a um cilindro e fazendo $90^{\circ}$ com o plano de projeção. As primeiras ideias de projeção de uma figura sobre um plano, muito provavelmente se originou da observação da projeção da sombra de uma árvore devido à luz do sol.

As primeiras projeções eram cônicas, exatamente como o olho humano vê as coisas. Isso pode ser confirmado quando se está em um grande corredor ou quando se olha um longo trilho de uma ferrovia. A sensação que se tem é que as linhas se encontram, quando na verdade são paralelas, ou seja, distância constante. Na sequência pensou-se na projeção cilíndrica oblíqua, ou seja, inclinada em relação ao plano de projeção e posteriormente na projeção cilíndrica ortogonal ou o método Mongeano. A Figura 1, a seguir, ilustra detalhes do conceito da projeção cilíndrica ortogonal.

Com o método Mongeano e os conceitos das coordenadas cartesianas e dos diedros de projeções, a Geometria Descritiva muito se desenvolveu, permitindo a representação gráfica bidimensional de peças e objetos através das normas e procedimentos do Desenho Técnico. 


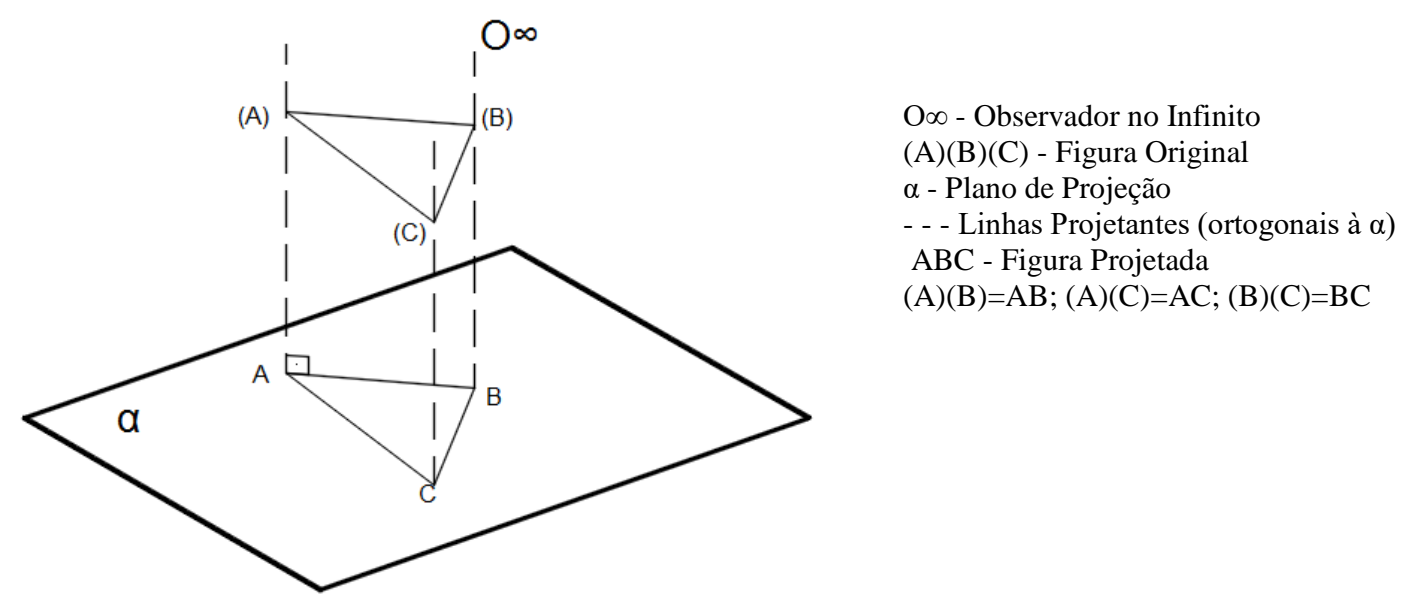

Figura 1 - Conceito de Projeção Cilíndrica Ortogonal.

Em 1795 Gaspard Monge (1746-1818), criou um método baseado na dupla projeção ortogonal de um objeto tridimensional (MONTENEGRO, 1991). Essas duas projeções, atualmente chamadas de vista de cima ou superior ou planta e a vista de frente ou frontal ou anterior, representadas em dois planos ortogonais ou perpendiculares (Horizontal ou $\pi$ e Vertical ou $\pi$ '), passaram a ser representadas em um único plano, através de um rebatimento, gerando o que se chama em Geometria Descritiva de épura, sendo a base conceitual do Desenho Técnico Projetivo.
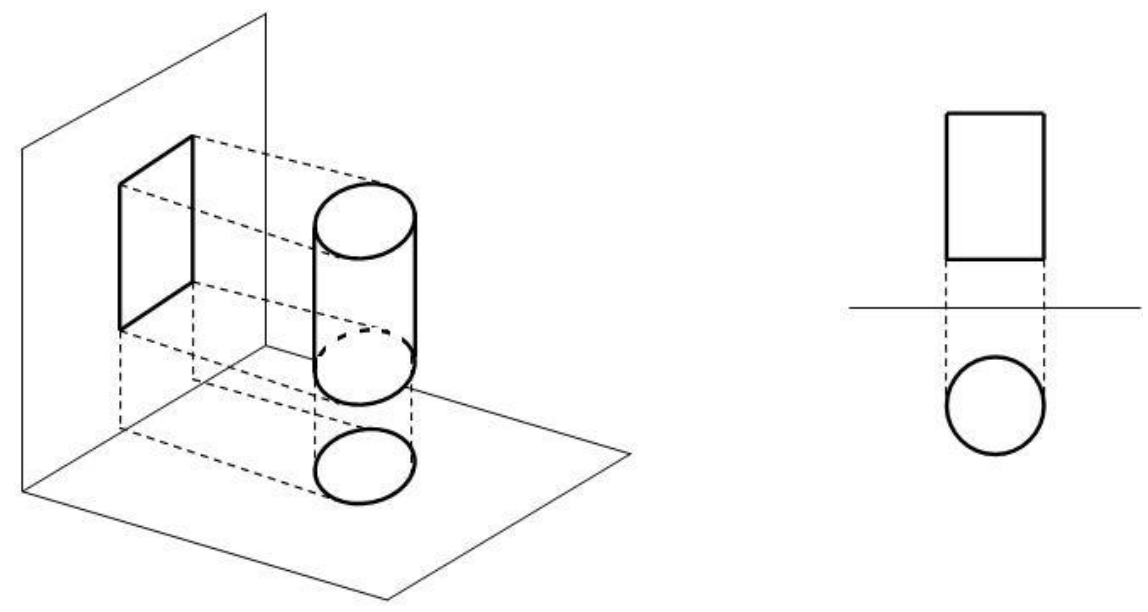

Figura 2 - A dupla projeção ortogonal (diedro) e sua épura ao lado.

Posteriormente criou-se o terceiro Plano ou Plano de Perfil, permitindo a representação em três vistas (Figura 3) e, no processo evolutivo do desenho projetivo chegou-se à concepção de imaginar o objeto no interior de um hexaedro ou cubo, permitindo a representação em até seis vistas.

O Desenho Técnico Projetivo, tal qual é representado hoje, século XXI, foi uma evolução dos princípios da Geometria Descritiva, devido à rápida necessidade dos problemas de engenharia, principalmente em função da $1^{\text {a }}$ Revolução Industrial que ocorreu entre 1780 e 1860 . A Figura 2 mostra a concepção original de Gaspar Monge, considerando-se a ideia dos planos horizontal $(\pi)$ e vertical $\left(\pi^{\prime}\right)$, configurando o que se chama de $1^{\circ}$ Diedro. No Brasil, os desenhos técnicos são concebidos no $1^{\circ}$ Diedro, enquanto em outros usa-se o $3^{\circ}$ Diedro. 

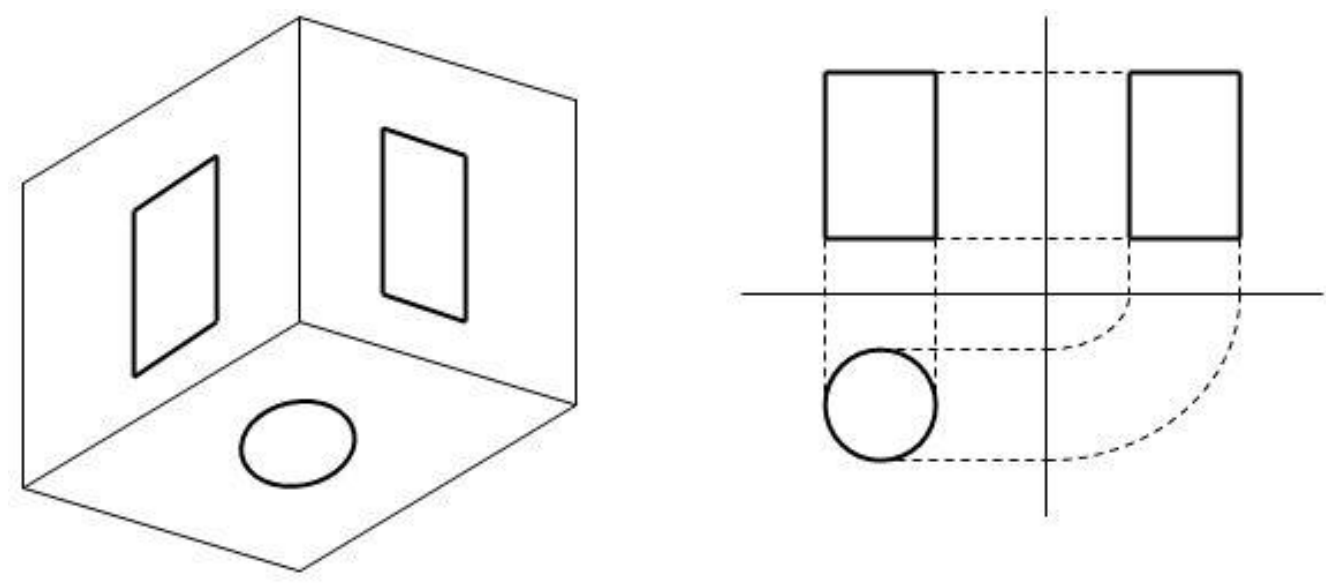

Figura 3 - Projeções no Triedro e sua épura ao lado.

\subsection{O Desenho Técnico Básico e Aplicado}

Uma vez que o futuro engenheiro já tenha domínio da representação das projeções cilíndricas ortogonais, conceituada na Geometria Descritiva, passa-se para o conceito do Hexaedro Básico, permitindo a projeção de um objeto por meio de seis planos, ou melhor, das Vistas Ortográficas. Do ponto de vista dos conteúdos, a disciplina Desenho Técnico, também chamada de Expressão ou Representação Gráfica em várias instituições, pode ser entendida como tendo duas partes: o Desenho Técnico Básico e o Aplicado.

Normalmente, na parte básica são estudados os seguintes conteúdos (por exemplo, na Uerj, campus Maracanã): letras, números e símbolos; tipos de linhas; escala numérica; perspectivas cônica, cavaleira e isométrica; cotagem; vistas auxiliares; cortes e seções. A parte prática do Desenho Técnico Básico compreende a execução de desenhos de peças e objetos, das mais diversas geometrias, objetivando a prática de toda a teoria.

No Desenho Técnico Aplicado, normalmente, são estudados os seguintes conteúdos, com a execução de desenhos específicos: arquitetura e construção civil; instalações hidrossanitárias prediais; instalações elétricas prediais; juntas soldadas; estruturas metálicas; fluxogramas de processo e engenharia; isométricos e plantas de tubulações industriais e arranjo físico (lay out) de instalações industriais.

Mesmo que sejam utilizados programas de computador para fazer os desenhos técnicos, é muito importante que os alunos desenvolvam habilidades manuais fazendo esboços ou croquis à mão livre. Nesses casos o ideal é que, antes de desenhar no computador, o aluno entenda o objeto ou peça e faça o croquis a lápis e à mão livre. Ou seja, o computador é apenas um recurso tecnológico que economiza tempo e permite uma melhor qualidade e detalhes das vistas ortográficas.

A propósito de executar desenhos técnicos via computador, em cursos de engenharia, cabem algumas observações. Inicialmente deve ser lembrado e ressaltado que, normalmente, na prática profissional, engenheiros não desenham, mas sim os desenhistas, já há alguns anos chamados de cadistas, uma vez que os primeiros programas foram tipo AutoCad®. Em verdade, engenheiros interpretam desenhos e ou fazem croquis à mão livre, para que os cadistas os desenhem com qualidade e precisão, via computador. Ou seja, não se recomenda que as disciplinas de Desenho Técnico ou 
Expressão/Representação Gráfica, para cursos de engenharia, sejam conduzidas apenas com cópias de desenhos feitos via computador.

Outra observação é que, em geral as disciplinas de Expressão/Representação Gráfica, são oferecidas nos primeiros períodos ou na parte básica dos cursos de engenharia, quando os alunos ainda não têm praticamente nenhuma informação sobre as disciplinas e conteúdos profissionais, seja qual for o curso. Em geral, só após dois anos de aprendizagem de como desenhar via computador, é que o aluno irá ter contato com disciplinas de cálculos e projetos aplicados à determinada área da engenharia. Normalmente, nessa fase ele já não lembra os comandos daquele programa específico que estudou, ou seja, a pouca prática de desenhar via computador perde o sentido. O ideal é que outras disciplinas específicas da parte profissional também exijam o uso de programas de computação gráfica. Ou seja, recomenda-se que, além das disciplinas de Expressão/Representação Gráfica no curso básico, os alunos também pratiquem via computador em outras disciplinas referentes a projetos, específicas de cada engenharia, fazendo a interrelação com os conteúdos de Desenho Técnico Básico e Desenho Técnico Aplicado.

\subsection{O Desenho Técnico com Auxílio do Computador}

Desenho auxiliado por computador ou CAD (do inglês: Computer Aided Design) é o nome genérico de sistemas computacionais utilizados pela engenharia, geologia, geografia, arquitetura e design para facilitar o projeto via desenhos técnicos. No caso do design, este pode estar ligado especificamente a todas as suas vertentes (produtos como vestuário, eletroeletrônicos, automobilísticos, etc.), de modo que os termos de cada especialidade são incorporados na interface de cada programa.

Estes sistemas fornecem uma série de ferramentas para a construção de figuras geométricas planas (linhas, curvas, polígonos, etc.) ou mesmo objetos tridimensionais (cubos, esferas, etc.). Também disponibilizam ferramentas para relacionar essas figuras como, por exemplo, criar um arredondamento entre duas linhas ou extrair as formas de dois objetos tridimensionais para obter um terceiro.

Uma divisão básica entre os sistemas CAD é feita com base na capacidade de cada programa em desenhar apenas em duas dimensões (2D) ou criar modelos tridimensionais (3D) também, sendo estes últimos subdivididos ainda em relação a que tecnologia usam como modelador 3D. Nos sistemas CAD pode haver intercâmbio entre o modelo 3D e o desenho 2D (por exemplo, o desenho 2D pode ser gerado automaticamente a partir do modelo 3D).

Existem modelos de CAD específicos que simulam as condições de fabricação, ou seja, as ferramentas usadas no desenho são as mesmas disponíveis no chão de fábrica. Estes são chamados programas CAM ou Computer Aided Manufacturing ou Manufatura Assistida por Computador. Também na arquitetura existem programas específicos que desenham paredes, telhados e outras construções automaticamente. Os softwares mais avançados usam a chamada modelagem paramétrica, que permite modificações do desenho pela simples entrada de números indicando dimensões e relações entre as figuras ou objetos desenhados. Em 2017 sistemas CAD como o AutoCAD e o Microstation Modeler dispunham do recurso de geração automática de vistas ortográficas, a partir do modelo sólido tridimensional.

Outro recurso tecnológico, que muito pode ajudar na formação do engenheiro é quando se conjuga a prática do Desenho Técnico via computador, com a impressão tridimensional (impressão 3D), mesmo para objetos ou peças simples. É muito importante o aluno, futuro engenheiro, saber representar um objeto tridimensional de forma bidimensional, via desenho técnico e, posteriormente ver aquela representação gráfica, materializar-se em um corpo sólido, logo, tridimensional.

DOI: $10.12957 /$ cadmat.2017.30484 


\subsection{Quais as principais habilidades cognitivas são exigidas dos engenheiros, na prática?}

A prática da engenharia, conforme inclusive experiência de diversos autores deste artigo, mostra que, fundamentalmente, engenheiros são resolvedores de problemas, precisando ter a capacidade de visualizar mentalmente e tridimensionalmente esses problemas antes de pensar em como resolvê-los. Essa prática comprova que, majoritariamente, engenheiros têm que ter bem desenvolvidas as seguintes habilidades ou inteligências: Verbo-linguística, Lógico-Matemática, Viso-Espacial e Pictórica.

Engenheiros têm que ter forte capacidade de interpretação de textos, bem como de se expressar de forma verbal e escrita, por exemplo, ao se apresentar para outros colegas ou para redigir um relatório. Estas são habilidades ligadas à inteligência Verbo-línguística. Engenheiros primeiro usam o raciocínio lógico, antes de inferir quais os conceitos e operações matemáticas devem ser empregadas. Engenheiros têm que ter uma boa capacidade Viso-Espacial, ou seja, ver mental e tridimensionalmente os problemas. Finalmente, engenheiros têm que ter boa capacidade, tanto de se expressar graficamente, quanto de saber interpretar Desenhos Técnicos, que nada mais são do que símbolos pictóricos.

Por tudo isto, confirma-se a importância do ensino/aprendizado do Desenho Técnico (ou Expressão/Representação Gráfica) em cursos de engenharia, uma vez que, tanto o estudo dos conceitos, quanto a execução de projeções cilíndricas ortogonais ou vistas ortográficas, muito ajudam a desenvolver as habilidades ou inteligências exigidas aos engenheiros.

\section{Referências}

BOANOVA, Cecília Oliveira. Análise de uma proposta de ensino de Geometria Descritiva baseada na perspectiva histórico-cultural. 2011. 112f. Dissertação (Mestrado em Educação) - Programa de Pósgraduação em Educação, Universidade Federal de Pelotas - RGS.

MONTENEGRO, Gildo A. Geometria Descritiva. Vol. 1. São Paulo, Blucher, 1991.

RABELLO, Paulo Sérgio Brunner. Ensino de Geometria Descritiva no Brasil. Revista SBPC Ciência Hoje, vol. 37, nov. 2005, p. 49 a 51.

TORRES, Elizabeth Amália Boscher, VIEIRA, Cláudio Luiz Baraúna e MARTINS FILHO, Protásio Dutra. A importância da Geometria Descritiva na Engenharia. XXVI Congresso Brasileiro de Educação em Engenharia - COBENGE. 1998, São Paulo, SP, Anais (p. 310 a 317). São Paulo, SP. 